\title{
Application of Human Resources Accounting at Haydom Lutheran Hospital
}

\author{
Article by Editha Daudi Lotto \\ MBA in Human Resources Management, Tanzania \\ E-mail: edithalotto@gmail.com
}

\section{Introduction}

The processes of all organizations are operated by human resource, thus valuation of this resource is very necessary and information concerning the valuation should be given to the management, investors and others through financial statements. Human resource accounting is fundamentally an information system that tells management what changes are happening over time to the human resources of the business. In the early 1990s, industries were familiar with the value and importance of human assets. When service sector started to contribute to a country's economy, the importance of human assets got prominence (Kamal Gosh Ray, 2010).

Human Resource Accounting (HRA) is concerns with accounting for the organization's management and employees as human capital that provides future profit. In the HRA approach, expenditures connected to human resources are reported as assets on the balance sheet as contrasting to the traditional accounting approach which treats costs associated to a organization's human resources as operating expense on the income statement that reduce profit. HRA suggests that in adding up to the measures themselves, the process of measurement has significance in decision-making concerning organizations. Though the origins and early development of HRA occurred typically in the United States, interest and contributions to development in the field have been evident in a number of other countries (Porwal L .S, 2007).

Human resources accounting can be defined as a process of accounting which quantifies, identifies and measures human resources to help management to cope up with the changes in its quality and quantum so that equilibrium could be achieved in between the needed resources and the provided human resources.

Briefly, human resource accounting is the art of recording, valuing, and presenting systematically the value of human resources in the books of account of the company. This definition brings out the following significant characteristic features of human resource accounting such as valuation of human resources, recording the valuation in the books of account and exposé of the information in the financial statements of the business (Baker \& McKenzie 2010).

\section{Objectives of human resources accounting}

The aim of HRA is to portray the potential of HR in monetary terms, at the same time as casting the organization's financial statements. The idea can be examined from two dimensions: (i) the investment in HR; and (ii) the value of HR. The investment in HR includes the expenses incurred for recruiting, staffing and training and developing the HR quality. The benefits of such investments are improved productivity and profit to the organization. The result that the investment generates is considered as the basis for HR value (Porwal L .S, 2007).

In short, the main objectives of HRA are to improve management by analyzing speculation in HR, consider people as its asset, attract and keep hold of qualified people, profile the organization in financial terms.

The major objective of human resource accounting is to facilitate the management to get information on the expenditure and value of human resources. HRA brings to beam the quantum of human resources and show the right control of conservation, appreciation and 
Texila International Journal of Management

Volume 2, Issue 2, Dec 2016

depletion of it in the right perspective. It provides data to the concerned persons about the cost of human resources and in the same way comparing it with the benefit obtained out of its utilization.

The objective of HRA is not just the recognition of the value of all resources used by the organization, but also includes the management of human resource which will improve the quantity and quality of goods and services. The fundamental objective of HRA is to facilitate the competence of human resource. It is basically adopted to consider human resources as assets, to generate information about human resources, to give value to human resources and to report human assets in the balance sheet (Bullen, M.L, 2007).

\section{Importance of human resource accounting}

Human Resource Accounting provides important information to the management, economic analysts and employees as stated below (Bras, F. A. \& Rodrigues, L.L, 2007).

1. Human Resource Accounting helps the organization in the Employment, locating and use of human resources.

2. It helps in decision about the training, promotion, transfers, and retrenchment of human resources.

3. It gives a basis for planning of material assets vis-à-vis human resources.

4. It helps in evaluating the expenditure incurred for imparting additional education and training in employees in terms of the profit derived by the firm.

5. It assists to identify the reason for high labour turnover at different levels and taking precautionary measures to contain it.

6. It helps in locating the genuine cause for low return on investment, such as improper or under-utilization of material assets or human resource or both.

7. It helps in understanding and assessing the internal strength of an organization and helps the administration to steer the company well through mainly adverse and unfavorable circumstances.

8. It provides important information for persons attracted in making long term investment in the organization.

9. It assists employees in improving their performance and bargaining power. It helps each of them to understand his input towards the betterment of the firm vis-à-vis the costs incurred by the firm on him.

\section{Methods of valuation of human assets}

There are various methods optional for the valuation of human assets. a lot of these methods are based on the assessment of physical and financial assets at the same time as others take into account human consideration. The main methods of valuation of human assert are historical cost, standard cost, present value of future earnings, replacement cost, and predictable realizable value. The main developments in HRA were started only during 1960's by a few of the organizations in USA (Porwal L S, 2007). Of course, the first effort to value the human being in monetary terms was made by William Potty who said that labor was the father of wealth and it have to be taken into account as making an estimate of wealth. On scanning through literature, the approaches to HRA can be generally classified as Cost Based Approaches, Monetary value based approaches and Non- monetary value -based approaches

\section{Cost based approaches has the following parts}

This method contains (i) Historical cost approach (ii) Standard Cost (iii) Replacement Cost (iv) Opportunity Cost

\section{(i) Historical cost approach}

This method has been developed by Flamholtz, Brumnetand Pyle. It is on the basis of real cost incurred on human resources. Such a cost might be of two types- acquisition cost and learning cost. 
Acquisition cost is the cost incurred on recruitment, selection; entire cost is taken into consideration counting those who are not selected.

Learning cost concern with expenses incurred on training and development. This method is very easy in its application but it does not indicate the true value of human assets. For example, an experienced employee may not need much training and therefore, his value may appear to be low although his real value is much more than what is recommended by historical cost method.

Actual cost incurred towards recruitment, hiring, training and developing human resources of the organization are grouped under this approach are capitalized and amortized over the future expected useful life of the human resources. Certain part of costs will be written off in percentage to the income of the future years which those human resources will offer service.

When these human assets are liquidated prematurely, the amount not written off is charged to profits of the year in which such liquidation takes place.

When the valuable life of the human resource is considered to be longer than initially expected, revisions are to be done in the amortization plan. The historical cost of human resource is almost related to the book value of the other physical assets. The extra costs incurred in training and developing is invested and is amortized over the remaining working life of the employee. The investment in human assets is the unexpired value.

\section{(ii) Standard cost Method}

David Watson has recommended this approach as an alternative of using historical or replacement cost, a lot of companies use standard cost for the valuation of human assets as it is used for physical and financial assets. By using standard cost, employees of an organization are categorized into dissimilar groups in reference to their hierarchical positions.

Standard cost is set for each category of employees and their value is calculated. This method is easy but does not consider differences in employees put in the same group. In many cases, these differences may be fairly vital (Bras, F. A. \& Rodrigues, L.L, 2007).

According to this approach, standard costs of recruiting, hiring, training and developing for each grade of employees are determined every year. The standard cost so arrived at for all human beings working in the organization are the value of human resources for bookkeeping purposes.

\section{(iii) Replacement cost}

Replacement cost propounded by Rensis Likert \& Eric G. Flamholtz insists on measure of cost to restore a firm's existing human resources. Human Resources are to be appreciated on the assumption that a new alike organization has to be created from scratch and the price to the firm is calculated if the existing resources were required to be replaced with new persons of corresponding talents and experience. It takes into account all costs concerning in recruiting, hiring, training and developing the replacement to the current level of efficiency. Tyagi CL, Madhu Tyagi, 2000)

Contrary to historical cost methods which take into account the real cost incurred on employees, replacement cost takes into account the theoretical cost that may be required to acquire a new employee to reinstate the present one. Replacement cost is normally much higher than the historical cost. For example, Friedman has predicted that the replacement cost of an executive in middle management level is approximately 1.5 to 2 times the present salary paid in that position.

Replacement cost is to a great extent better indicator of value of human assets despite the fact that it may present certain operational problems. For example, accurate replacement of a person may not be found simply with whose cost the valuation is done. This approach is more sensible as it incorporates the present value of the organization's human assets in its financial statements presented at the end of the year (Bullen, M.L, 2007). Expenses incurred by an organization in replacing an employee who terminated are known as replacement cost like the following - 
Texila International Journal of Management

Volume 2, Issue 2, Dec 2016

(a) Staff Meetings (b) Travel Cost (c) Employment Medical Examination (d) Communication of job ability (e) Pre-employment administrative functions (f) Interviews (g) Testing

\section{(iv) Opportunity cost method}

This approach was advocated by Heckiman and Jones at first. This also recognized as "Market Value Method". Market value technique is used to measure the worth of human resources which is based on the economist's idea of "opportunity cost.

Opportunity cost is the value of an asset once there is an alternative chance of using it. In this method there is no opportunity cost for those employees who are not in short supply. As such only scarce people should form component of the value of human resources. The employee is considered as inadequate only when the service in one division of an individual or group denies this type of talent to another division. Thus the opportunity cost of an employee in individual department is calculated on the base of offer made by another department for the employees working in this department in the similar organization (Bullen, M.L, 2007).

\section{Monetary value based approaches}

In this approach, the value of human resources of an organization is determined according to their current value to the organization. For determination of the current value, a number of valuation models have been established. Some of the important models are as follows -

\section{(i) The lev and schwartz model}

The present value of future earnings method has been developed by Schwartz and Lav in 1971. According to this model, the worth of human resources is determined as follows -

1. All employees are divided in specific groups according to their age and proficiency.

2. Average annual salary are determined for various ranges of age.

3. The total salary which each group will get up to retirement age are calculated.

4. The total salary calculated as above are discounted at the rate of price of capital. The value thus obtained at will be the value of human resources/assets.

5. The subsequent formula has been recommended for calculating the value of an employee according to this model -

$\mathrm{V}=$ the value of the person's annual earnings up to the retirement 45

$\mathrm{t}=$ age of retirement

$\mathrm{r}$ = present age of the employee

$\mathrm{R}=$ discount rate

\section{(ii) Reward valuation method- flamholtz model}

This model has been developed by Flamholtz in 1971. This is an improvement concerning "present value of future earnings model"seeing that it takes into consideration the possibility or probability or an employee's movement from one position to another in his profession and also of his leaving the firm earlier, that his retirement or death.

According to this model, the final measure of an individual's value to an organization is his expected realizable value. Predictable realizable value is based on the assumption that there is no direct relationship connecting cost incurred on an individual and his value to the organization at a particular point of time. An individual's worth to the organization can be defined as the present value of set of future services that the expected to provide throughout the period he remains in the organization (Bullen, M.L. 2007).

Flamholtz has agreed the variables affecting persons expected value, individual conditional values and his probability of remaining in the organization. The former is function of the individual's abilities and activation level, whereas the later is a function of such variables as job satisfaction, commitment, motivation and other factors. 


\section{(iii) Net benefit model (morse model)}

This approach has been recommended by Morse in 1973. This approach explain that, the value of human resources is corresponding to the present value of net benefits derived by the organization from the service of its employees (Bullen, M.L. 2007). The method includes the following steps:

1. The gross value of services to be offered in future by the employees in their personal as well as their collective capacity is determined.

2. The value of future expenditure (equally direct and indirect) to the employees is determined.

3. The surplus of the value of future human resources (as for each 1 above) over the value of future payments (as per 2 above) is ascertained. This, as a issue of fact, represents the net profit to the organization on account of human resources.

4. The present value of the net profit is determined by applying a predetermined discount rate (in general the cost of capital). This total amount represents the value of human resources to the organization

\section{Value -based approaches or Non- monetary}

\section{(i). Pekin ogan model}

Certainty Equivalent Net Benefit Model has been suggested by Pekin Ogan in1976. This, as a matter of fact, is an extension of "net benefit approach" as recommended by Morse. According to this approach, the confidence with which the net benefits in future will accrue should also be considered, while determining the value of human resources (Bullen, M.L., 2007). This approach requires determination of the following -

1. Net benefit from every employee.

2. Confidence factor at which the profit will be available

3. The net profit from all employees multiplied by their confidence factor will give certainty equivalent net benefits. This will be the worth of human resources of the organization.

\section{(ii). S.K. chakraborthy model}

Aggregate payment approach advocated by Indian author Prof. S.K. Chakraborty in 1976. He has valued the human resources in collective and not on an individual basis. He suggested that managerial and non-managerial man power can be evaluated independently. The value of human resource on a collective or group basis can be is multiplied by the average term of employment of the workers in that group and is the investment in human resource.

The average yearly salary payments for the next few years could be found out from the salary grade structure and promotion schemes of the organization. The recruitment, including selection, development and training expenses of each employee could be recorded separately and considered as deferred revenue expenditure to be written off over the anticipated average occupancy of the employee in the organization. The deferred part should be shown in the financial statement of the organization. In case of permanent exit on due to death, retrenchment etc. then the balance on the deferred revenue account of that year of that person should be written off next to the income in the year of exit itself (Boedker, C., Mouristan, J. \& Guthrie, J. 2008).

For the reason of finding the present value of projected payments the expected average after tax return on capital employed over the average occupancy period should be taken as the discount rate.

Concerning disclosure of accounting information on human resources as an asset, he has recommended to include human assets under investments in the 'financial statement' of the organisation. He is not for taking it as 'fixed assets' as it will lead to problems of depreciation, capital profit or losses upon exit etc.; neither it could be in use as current asset as it will not be in consistency with the general meaning of the term 
Texila International Journal of Management

Volume 2, Issue 2, Dec 2016

\section{Human capital}

The Human capital means the basic skill, capabilities, the perception, know-how and expertise. Every individual has particular skills and understanding. The education one has undergone should help him to extend knowledge in general. Until one gets basic employment he is not keen on planning his future and there is uncertainty. This is usual in most of the cases except a few. As one is located in an organization in some position, he starts to look for elevation (Singh YK and RawatHS, 2006). The organization also would tap his basic skill and capabilities and redirect them to achieve the goals of the organization and in the process it attempts to build up his basic skill through proper training, motivation and direction. The human capital is correctly put through for effective functioning, right decision making and profession development. Generally all these it creates value to the organization and makes it more steady in the competitive environment (Andrikopoulos, A, 2005).

People are our most significant resource' has in fact come to mean something. Today more than ever the management realizes that the most capable asset in an organization is its people. In fact it is outdated to say people are the most important asset, relatively they are the only dynamic asset. Nothing happens without people, money, technology, equipment etc. Nothing means anything without a human to act. Therefore, the management has slowly realized the importance which in turn has edged Human Resource (HR) from the locale into mainstream organizational strategies. Having moved to the center stage is not the end. It has to maintain its stand and move even further and for that to happen HR have to learn the language of administration and organizations i.e. it has to talk in quantitative and objective terms. Time and again, every manager has for all time stated 'You can't manage what you can't measure'. Companies are managed with quantitative data. Every organization has its eye on the bottom line-profit and all the units work to show their contribution to service, quality and performance. It is to be remembered that every unit affects business results and every job is a value-adding operation. Hence, it is very important to be able to measure this contribution objectively.

\section{Intellectual capital}

Tangible assets can be simply valued. How does one evaluate intangible assets such as service standards, creativity etc., Intellectual capital such as knowledge, information, skill, experience etc, which helps create wealth that can't be effortlessly assigned a price? To date, there is no clear conformity in the accounting profession about how to account for them. (Andrikopoulos, A. 2005).

So far the role of intangible assets such as brand names, patents intellectual capital, patents etc., in their contribution to boost the amount of wealth in firms can't be ignored. The shift to a knowledge-based economy has created completely different categories of assets, popularly known as soft assets that are not known in financial statements.

\section{Valuing intellectual capital}

Human Capital, Customer Capital and Structural Capital include of a company's Intellectual Capital. Although all are intangible, they can be measured and targeted for investment.

Human capital represents knowledge; skills and capability to give solutions to problems that customers think are significant. Enabling human capital requires other structures such as customer files, software manuals, etc. Customer capital is the value of an organization's relationship with whom it does business as well as suppliers (Andrikopoulos, A, 2005). HR professionals have always been trying to develop measures to value human capital. A number of the measures utilized are:

\section{Measures of innovation}

Real innovation always commands a premium. All companies are always striving to be dissimilar from the other companies and to stand out from the rest. In this endeavor, new 
products, ideas, and strategies are the order of the day and now companies are [earning to review this aspect of inventiveness in the language it well understands, that is the language of finance.

\section{Measuring employees' attitude}

On top of all it is only employees' attitude about the job and the company, which gets reflected in their behavior towards the clients. That behavior in turn translates into customers 'retention, loyalty and recommendations which in turn get reflected in financial performance. Therefore, behaviors and attitudes that have an effect on performance are being measured. A number of the attitudes measured are satisfaction, commitment, locus of control, organizational involvement and motivation: and the behaviors frequently measured are performance, adjustment, absence or illness and voluntary turnover (Palanivelu VR,2007).

\section{Measures of tenure, absenteeism, turnover, experience and learning}

These indices that comprise of a organization's inventory of knowledge workers need to be quantified. Quantifying tenure, absenteeism, turnover, and experience is quite simple when compared to learning. Turnover usually represents a substantial cost to business. In measuring turnover, an organization has to think about three major, separate cost categories: Separation costs, replacement costs and training costs. In addition, the variation in currency-valued performance between those parting and their replacements should also be considered.

Likewise, the rate of absenteeism is first calculated and then the cost of absenteeism can be estimated using set formulae and procedures. This cost would include employee-hours lost, supervisory hours lost, all other costs incidental to compensation, absenteeism, benefits, etc (Andrikopoulos, A. 2005).

\section{Structural capital measures}

Transporting, sharing and enabling human capital require other structures or organizational capabilities. Structural capital includes everything that remains when the employees go home namely, software manuals, databases, trademarks, customer file and organizational structures. In order to find out if a company's systems are helping or hindering its employees to do to their optimal level measures such as suggestions versus implementation, production-to market time, databases at estimated costs, etc., are accounted(Bullen, M.L.2007).

\section{Customer satisfaction measures}

There are a lot of objective ways to measure customer satisfaction. Some of the common measures are brand equity, customer retention, and customer satisfaction. Then customer satisfaction is connected to performance management for each employees it can generate supportive data for the 360 degree feedback of employees (Baker \& McKenzie, 2010).

Earlier for HR programs it was enough just to collect data and calculate the cause and effect of those programs. Nowadays, the ultimate aim is to evaluate not the return on investment and business impact but also to be able to change these data into financial values and compare them with the HR's fully loaded costs.

\section{Studies related to human resource accounting}

Some authors have expressed views suggesting the benefits of HRA measurements and the procedure of measuring human resources. For example Johanson \& Mabon (1998) indicate that expressing human resource interventions in monetary terms and /or cost benefit terms is more effective than using soft accounting information such as data on job satisfaction. Since the traditional function of accounting is the determination of the value of the financial activity, performing analysis with hard numbers such as cost-benefit analyses assist us determine how resources should be utilized by human resources for various interventions. Toulson \& Dewe (2004) conducted a survey study utilizing constituent analysis and found two reasons why measuring human resources is significant. 
Texila International Journal of Management

Volume 2, Issue 2, Dec 2016

The first is that dimension reflects the strategic and competitive significance of human resources, and the second suggests that to earn trustworthiness, human resources must be articulated in financial terms. McKenzie \& Melling (2001) suggest that, if correctly implemented, the human capital planning and budgeting process will become a key driver of strategy in that strategic human capital setting up and budgeting ensures that the most excellent resources are mobilized for each internal process. They point out that too often organizations focus $100 \%$ on meeting the financial budget first without thought of the effect the cost slashing will have on strategy, and note that the financial numbers are a lagging pointer of where a firm has been and should not be substituted for foremost indicators of where the firm is going. To a certain extent management should focus clearly on causal, leading indicators that drive winning financial measures, and that it is by skills-based budgeting that the misleading notion of financial focus can be avoided. It is recommended by Moore (2007) that the value of human capital should be more entirely considered when making decisions about the acquisition and removal of people-and notes that the accounting practices at present employed by companies can have an excessive influence in driving the strategic decisions of these companies. Moore comments that there are parallels between the process of hiring an employee (a human capital asset) and that of acquiring a fixed capital asset. Though while most companies acknowledge the contributions of its workers, they do not think of the gaining or disposal of human capital assets in the same way or with the same considerate planning or strategic thinking as they do fixed capital assets.

\section{Application of HRA to haydon lutheran hospital}

The purpose of this project is to introduce a concept of Human Resources accounting to Haydom Lutheran Hospital (HLH) Management. Haydom Lutheran hospital is a Faith Based Organization and belongs to Evangelical Lutheran Church of Tanzania, Mbulu Diocese. The hospital provide service approximately 500 patients and have more than 600 employees. The hospital has all necessary medical departments with varieties of specialty services and is among regional referral hospitals in Tanzania. HLH started in 1955 with 50 beds for admition and with less than 50 staff. It was providing primary health care services.

Currently, the hospital has expanded to the extent of providing specialty services. The expansion has been achieved in many areas including infrastructure, medical and social services, professional and research activities. Despite of this improvement, HLH is still using the traditional accounting approach. Traditional accounting approach treats costs connected to a company's human resources as expenses on the income statement that reduce profit as opposed to HRA approach in which expenditures related to human resources are reported as assets on the balance sheet. HRA suggests that in addition to the procedures themselves, the process of measurement has relevance in decision-making involving organizations. There is a need of HLH shifting from the traditional accounting approach to HRA accounting. As Human resources manager at HLH, adoption of HRA will facilitate to improve my work by analyzing investment in HR, attract and retain qualified people, consider people as an asset, and profile the organization in financial terms. The purpose of this project is to introduce Human Resource Accounting to the Haydom Lutheran Hospital organization.

\section{World demand of human resource accounting}

It is factual that, the 21st century is era of Human demand, countries those have labor quality ruling the world with leading technology countries like china and Japan forerunners in technology improvement, is all outcome of work force performance. Therefore whole world realized that human resource is the genuine investment into business ventures that should only grab and stick the success waves. It can be say that INFOSYIS, DR. REDDY`S, Bharat heavy Electrical Ltd (BHEL), and Steel Authority of India Ltd (SAIL) are still profit generators because acknowledged value of quality of labor and ordered climax priority so as company`s yields ripped fruits with help of ripped force (quality employees) and can stand in opposition to any business storm and cope up effectively (Kamal Gosh Ray, 2010) 


\section{Conclusion}

Human resource is one of the most significant back office operations of any organization or business. The skills, ability and creativity of human cannot be replaced by machines. We can lose competence in work if there is no qualified person in on work. At all areas and levels of the business or firm human efficiency is required with machine efficiency. A person can work without machine but machine can't. For this reason, industry like advertising and direct marketing for example human talent is more costly among other else. No machine can ever come up with a sole advertising idea without the human input. For these reasons, all companies are advised to learn, recognize and be grateful for value of their employees by applying human resources accounting as they are value and capital investments. The author of this project has great positive anticipation on application of HRA by Haydom Lutheran Hospital thus will change an existing system of traditional accounting.

\section{References}

[1] Andrikopoulos, A. (2005),Using intellectual capital statements to determine value drivers and priorities for organizational change, A portfolio selection approach, Knowledge Management Research \& Practice 3 (3), 166.

[2] Boedker, C., Mouristan, J. \& Guthrie, J. (2008), Enhanced business reporting, International trends and possible policy directions; Journal of Human Resource Costing \& Accounting, 12 (1), 14.

[3] Bras, F. A. \& Rodrigues, L.L. (2007). Accounting for firms' training program, Journal of An exploratory study, Vol. 11 (3), 229

[4] Bullen, M.L. (2007), Human resource accounting; A useful tool for measurement and management in organizations; Leadership and Organizational Management Journal Vol;12.(3)85-103.

[5] Baker \& McKenzie (2010), Australian Master Human Resources guide, CCH Australia Limited. Macquarie University. Graduate School of Management; Australia

[6] Human Resource Management Journal, 14 (2), 75-90.

[7] Johanson, U. \& Mabon, H. (1998). The personnel economics institute after ten years :

[8] Jelsy joseph, Kuppapally (2008), Accounting for Managers, Journal of Accounting Review Jaipur. Vo II.1991, Prentice-Hall of India, New Delhi

[9] Kamal Gosh Ray (2010), Mergers and Acquisitions, Infosys annual financial statement, prentice Hall of India private limited, New Delhi

[10] Moore, R. (2007). Measuring how 'human capital' appreciates in value over time,

[11] Plant Engineering Journal Vol. 61 (4), 29.

[12] Tyagi CL, Madhu Tyagi (2003), Financial And Management Accounting, Atlantic Publishers and Distributers. New Delhi

[13] Palanivelu VR (2007), Accounting for management. Lakshmi publishing (p) Limited. New Delhi

[14] Porwal L S (2007). Accounting Theory. Tata McGraw-Hill. New Delhi

[15] Singh YK and Rawat HS (2006), Human Resource Management. A.P.H. Publishing Corporation. New Delhi:181-182

[16] Toulson, P.K. \&Dewe, P.(2004). HR Accounting as a Measurement Tool.

[17] What has been achieved and where we are we going?” Journal of Human Resource Costing and Accounting, 3 (2), 65-76. 